\title{
The functional importance of parasites in animal communities: many roles at many levels?
}

\author{
Robert Poulin* \\ Department of Zoology, University of Otago, P.O. Box 56, Dunedin, New Zealand
}

Received 22 October 1998; accepted 19 November 1998

\begin{abstract}
Past research on parasites and community ecology has focussed on two distinct levels of the overall community. First, it has been shown that parasites can have a role in structuring host communities. They can have differential effects on the different hosts that they exploit, they can directly debilitate a host that itself is a key structuring force in the community, or they can indirectly alter the phenotype of their host and change the importance of the host for the community. Second, certain parasite species can be important in shaping parasite communities. Dominant parasite species can directly compete with other parasite species inside the host and reduce their abundance to some extent, and parasites that alter host phenotype can indirectly make the host more or less suitable for other parasite species. The possibility that a parasite species simultaneously affects the structure of all levels of the overall community, i.e. the parasite community and the community of free-living animals, is never considered. Given the many direct and indirect ways in which a parasite species can modulate the abundance of other species, it is conceivable that some parasite species have functionally important roles in a community, and that their removal would change the relative composition of the whole community. An example from a soft-sediment intertidal community is used to illustrate how the subtle, indirect effects of a parasite species on non-host species can be very important to the structure of the overall community. Future community studies addressing the many potential influences of parasites will no doubt identify other functionally important parasite species that serve to maintain biodiversity. (C) 1999 Australian Society for Parasitology Inc. Published by Elsevier Science Ltd. All rights reserved.
\end{abstract}

Keywords: Biodiversity; Ecosystem engineering; Indirect interactions; Intertidal community; Modified host phenotype; Trematodes

\section{Introduction}

It is probably safe to say that for each species in a community of free-living animals, there is at least one species of parasite. Parasites account for only a fraction of the biomass in the overall community, and to most ecologists throughout

\footnotetext{
* E-mail: robert.poulin@stonebow.otago.ac.nz
}

this century they have been not only invisible but unimportant. This view has changed slowly over the past 15-20 years, and now a bridge exists between parasitology and community ecology. This new perspective is due mostly to recent research progress in two distinct areas. First, field and laboratory studies have indicated clearly that some parasite species have key structuring roles in communities of free-living animals [1-3]. These parasites can affect the relative abundance 
of different animal species in the same way that a top predator could, justifying the inclusion of parasitism as a biotic force capable of determining the biodiversity of communities. Second, there has been much interest in the communities formed by parasites themselves inside their hosts [4-6]. Individual hosts represent self-contained, well-defined habitats as well as replicate units, making it easier to test general ideas in community ecology with assemblages of parasites than with free-living animals.

Despite the important results emerging from these two lines of research and the obvious links between them, there have been no attempts at integrating them. In other words, interactions among parasites within hosts and effects of parasites on host communities are always examined separately. It may be that a parasite species that influences the composition of the parasite community to which it belongs could also be a key factor structuring the community of free-living hosts. There is a need to look at the roles of parasites simultaneously at both hierarchical levels of the overall community to determine how important they are in the maintenance of biodiversity.

To do this, however, we need a way of assessing the importance of particular species for the community. Ecologists have long recognised that not all species are equal in terms of their influence on the structure of communities: some have more influence than others on the composition of the community. Payne [7] coined the term 'keystone' species to describe these important species. He defined a keystone species as a species, usually high in the food web, that greatly modifies the species composition of communities. The concept is appealing, but the notion of keystoneness has been criticised frequently [8], mainly because there is no operational or quantifiable definition of keystone species that would allow one to categorise species as keystones or not. A better alternative may be the concept of functional importance proposed by Hurlbert $[8,9]$. The functional importance of a species can be quantified as the sum, over all species in the community, of the changes (whatever their sign) in abundance or productivity which would occur following the removal of that particular species from the community. Measuring functional importance is not easy; in the case of parasitic species it would require their complete removal from a community, a feat that is virtually impossible. Nevertheless, it is often possible to estimate roughly how important a species is to others. How would parasite species in general fare in the overall community? Could some parasite species have a functional importance equal to or greater than that of free-living species? Certainly some parasite species would be functionally important at the level of the parasite community, whereas maybe one or two would be important at the level of the assemblage of freeliving animals. The functional importance of a parasite must be assessed simultaneously across both levels of the entire community. When this is done, surely some parasites will emerge as key factors serving to maintain biodiversity.

Here, I will try to integrate the potential importance of parasite species across all levels of a community. Wherever possible, I emphasise the importance of indirect influences of parasites as opposed to the more obvious direct effects, mainly because indirect effects have been systematically ignored in previous studies. First, I will briefly review the ways in which parasites can be functionally important for the free-living animals in a community. Second, I will discuss how some parasites can have a disproportionate functional importance within the community of parasites. Finally, I will present an example from the New Zealand intertidal community in which the functional importance of a parasite species has been evaluated across several levels in the community. This example is taken from work in progress, and is meant only to illustrate how the study of parasitism and community ecology can be approached at the larger scale of the overall community.

\section{Structuring communities of free-living animals}

There are at least three ways in which parasite species can affect the community of free-living organisms among which they live. First, if differ- 
ent free-living species have different susceptibilities to the same parasite species, then that parasite may be functionally important in that it depresses the abundance of some host species more than that of others. If that parasite were removed from the community, the relative abundance and possibly the composition of free-living species would change. Second, a parasite species may directly decrease the functional importance of its host species in the community of free-living animals via pathological effects. Third, a parasite species may indirectly increase the functional importance of its host species in the community of free-living animals through some parasite-induced alteration in host phenotype. These three processes are illustrated in Fig. 1. They are not mutually exclusive but are here discussed in turn because they have always been studied independently.

\subsection{Differential effects on different host species}

Parasite species can mediate the coexistence of the host species they exploit simply by harming some host species more than others. A nonspecific parasite, parasitising related host species in a frequency-dependent manner, or a more host specific parasite with a preference for the competitively superior host species, could help maintain a high host species diversity [3]. If that parasite were to disappear, then the superior competitor, or the host species with the highest intrinsic rate of population growth, could rapidly increase in abundance at the expense of other species, perhaps driving these other species to local extinction (Fig. 1a).

There are numerous examples of parasite species having a functional importance in this way. Park [10] first showed this in classical experiments on flour beetles. He maintained laboratory populations of Tribolium castaneum and Tribolium confusum over several years, either in single-species or mixed-species containers. When the two beetle species were kept together, T. castaneum usually drove $T$. confusum to extinction, suggesting that $T$. castaneum was the superior competitor. However, some containers holding both species at the onset of the experiment also contained the sporozoan parasite Adelina tribolii, which lives in the beetles' haemocoels and is transmitted by oocysts passed in the hosts' faeces. When the parasite was present it was $T$. castaneum that became extinct [10]. Separate tests confirmed that the sporozoan had a greater negative effect on $T$. castaneum than on $T$. confusum. The parasite thus nullified the competitive edge held by $T$. castaneum over $T$. confusum, and it reversed the outcome of interspecific competition between the beetle species. The functional im- a)

PARASITE ABSENT

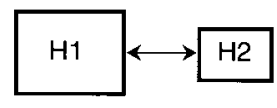

b)

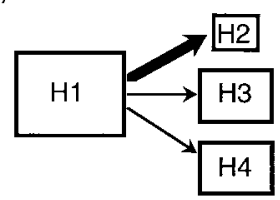

c)

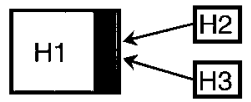

PARASITE PRESENT

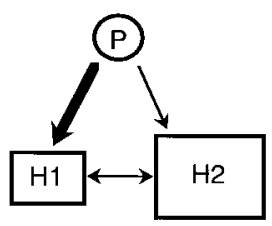

Fig. 1. Schematic representation of three possible effects of parasites on communities of free-living organisms. The parasite species, P, can (a) have different pathological effects on different host species, $\mathrm{H}$, and influence their relative abundances; (b) have a negative effect on a functionally important host species and thus indirectly affect other free-living species; or (c) alter the phenotype of its host species in a way that changes the host's functional importance for other species. The alteration in host phenotype is illustrated by the black shading. The relative abundances of different species with and without the parasite are indicated by the sizes of the different boxes. Competitive interactions are illustrated by two-way arrows; other arrows indicate one-sided exploitative interactions. The strength of the interaction is proportional to the thickness of the arrow. 
portance of this parasite may allow the coexistence of the two beetles in nature. It is interesting to note that another parasite (the cestode Hymenolepis diminuta) shared by both beetle species has the opposite effects, i.e. it benefits the superior competitor $T$. castaneum in competitive situations [11]; the net effect of this parasite may be to accelerate the extinction of $T$. confusum and not to maintain biodiversity.

Studies of congeneric amphipod species living in sympatry in littoral habitats and sharing parasite species also provide good examples of the functional importance of parasites. The amphipod Gammarus insensibilis has a higher fecundity and rate of population increase than its congener Gammarus aequicauda, yet the two species are frequently found coexisting. They both serve as first intermediate host for the trematode Microphallus papillorobustus; field evidence, however, indicates that only $G$. insensibilis suffers from parasite-induced mortality [12]. Similarly, the amphipods Corophium volutator and Corophium arenarium also coexist and also share a trematode parasite, Microphallus claviformis. Laboratory tests suggest that $C$. volutator is the superior competitor but also that it incurs higher mortality from parasitism by the trematode than C. arenarium [13]. In both cases, the parasite happens to have more harmful effects on the competitively superior species, thereby cancelling out its advantage and promoting its coexistence with a congener.

There is some evidence that the introduction of avian malaria to the Hawaiian islands has altered the species composition and spatial distribution of land bird communities [14,15]. This presumably resulted from the differential pathology incurred by the different bird species. A similar scenario also takes place in other systems involving vertebrate hosts $[16,17]$. The conclusion is essentially the same in all these examples: if it were possible to exclude the parasite from the community, we would expect marked changes in the relative abundance of host species. This structuring influence of parasites is probably very common, since many parasite species exploit at least two related host species and it is very unlikely that they cause identical pathological effects in all the host species they exploit. In fact, we might even include all situations where a parasite species exploits one host species only as cases of differential effects on host species. If the parasite has a negative effect on the survival of its host, and if its removal from the community would alter the relative abundances of the host species and its relatives or competitors, then the parasite plays a functionally important role just as if it exploited different species with different pathological effects.

\subsection{Direct effects on a functionally important host species}

Because many parasites have debilitating effects on their hosts, it is reasonable to suppose that a host species playing a functionally important role in the community of free-living animals could have its importance decreased by parasitism. A top predator, for instance, may exhibit reduced activity and/or food intake when parasitised. If so, the parasite species directly causing the reduction in food intake would have a functionally important role in the structuring of the community of organisms that serve as prey for the predator (Fig. 1b).

There are no documented examples of this phenomenon in animal communities. However, there is some evidence that the gastrointestinal nematodes of herbivores can have an impact on plant communities by inducing a reduction in the appetite of their hosts [18]. The consequences for plants of appetite suppression in herbivores are that species preferentially grazed by herbivores can become locally more abundant. No doubt the same sort of thing takes place in predatorprey systems in which predators are exploited by debilitating parasites.

\subsection{Indirect changes in the functional importance of a host species}

Another way in which parasites can influence community structure would be by indirectly (i.e. not via pathology) modifying the functional importance of their host species in the community. For instance, they could dramatically increase 
the importance of the role played by their host in the community via a parasite-induced change in host phenotype. The alterations caused by parasites in host morphology, colouration or behaviour are well documented [19-21]. These changes in host phenotype can result in an increase or decrease in the availability of resources for other species. Ecologists have labelled as ecosystem engineers those organisms that directly or indirectly modulate the availability of resources to other species by causing physical state changes in living or non-living material [22,23]. Ecosystem engineers have large effects on community processes by maintaining or creating ecological niches for other species. The role of parasites as ecosystem engineers is only now being examined [24]. In changing the phenotype of a host from one state to another, parasites could create new resources for other species, by making the host or part of its body available as a resource to other organisms (Fig. 1c).

Examples of this phenomenon are still very few, but probably only because of a lack of study. For instance, it is common for crabs parasitised by rhizocephalan crustaceans to harbour a much richer epibiont community than non-parasitised crabs [24]. Rhizocephalan parasites develop an extensive network of branches inside their crab host and completely alter its physiology [25]. An important consequence of infection is that parasitised crabs do not moult; their cuticle thus represents a much more permanent substrate for epibiotic invertebrates (barnacles, polychaetes, etc.) than that of nonparasitised crabs. Often these epibionts are very specific when it comes to choosing a substrate, and would not exist in the local community without the availability of some minimum amount of substrate. The effect of the parasite may thus be the creation and maintenance of a key resource (attachment substrate); once parasitised, crabs become functionally important for the rest of the invertebrate community. Other parasites can also interfere with their host's moulting, or alter other aspects of host phenotype that determine how much substrate (or another resource) is available for other organisms. Another example of how a parasite can act as an ecosystem engineer will be given below where I discuss a host-parasite system in the New Zealand intertidal zone.

\section{Structuring communities of parasites}

Parasite species within a host themselves form a distinct subset of the overall community. Because they share a microhabitat and other resources, interactions among parasite species are common and are important in structuring parasite assemblages. There are, however, ways in which the presence of one parasite species can influence the presence and abundance of another without any direct interaction taking place between these species. Here I will briefly discuss two general ways (Fig. 2) in which a parasite species can have a functionally important role in the structuring of parasite communities. I have used the presence or absence of direct interactions between parasite species as a criterion for classifying the processes involved in parasite community structure. Surely other arrangements are possible, but the direct versus indirect comparison serves to highlight a whole array of potential processes that are in need of further research.

\subsection{Direct interactions between parasite species}

Various interactions are possible between cooccurring parasite species. For instance, the larval stages of trematodes in their molluscan intermediate host can prey on the smaller larval stages of other trematode species [26,27]. The most common form of interspecific interaction among parasite species, however, is straightforward competition for space, food or other resources. In concurrent infections of parasites that live in the same host organ, such as the intestine, large reductions in the abundance of at least one parasite species are frequently observed in relation to single species infection $[21,28]$. Often, the effects of interspecific competition between parasitic species are asymmetrical, i.e. species $\mathrm{A}$ has a much greater negative effect on the abundance of species $\mathrm{B}$ than $\mathrm{B}$ has on the 
PARASITE

ABSENT

a)
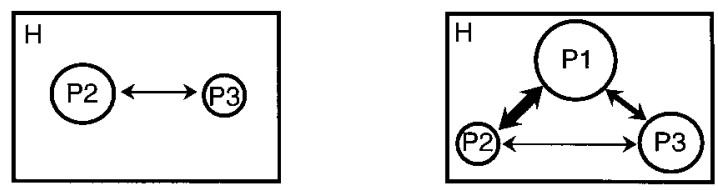

b)

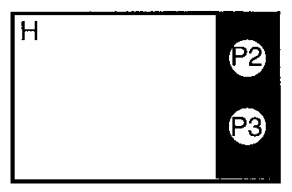

PARASITE

PRESENT

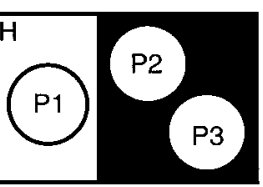

Fig. 2. Schematic representation of two possible ways in which a parasite species may influence the abundance of other parasite species with which it shares a host, H. The parasite species P1 can (a) directly compete for host resources with parasite species P2 and P3 and change their relative abundance; or (b) modify the host phenotype in a way that makes the host more suitable for the other parasite species. The alteration in host phenotype is illustrated by the black shading. The relative abundances of different species with and without parasite $\mathrm{Pl}$ are indicated by the sizes of the different circles. Competitive interactions are illustrated by two-way arrows; the strength of the interaction is proportional to the thickness of the arrow.

abundance of A. In some types of parasite communities, such as assemblages of larval trematodes in molluscs [29], asymmetrical reductions in abundance are often extreme, leading to the exclusion of one parasite species from hosts harbouring another, more dominant parasite species. What determines which species is most negatively affected in a pair of competing parasite species may be either simply a function of which one first established in the host, or it may be some intrinsic biological property such as body size [29]. Whether or not competitive exclusion takes place, it is clear that many parasite species have functionally important roles in parasite communities relative to other species, and that the community would be different if they were excluded (Fig. 2a).

One factor that often acts to temper the effects of competition among parasites is their ability to

adjust their niche in response to the presence of a competing species $[30,31]$. Thus, instead of a numerical response (i.e. a change in relative abundance), the presence of a competitor may lead to a functional response instead, or a niche shift [21]. This is commonly referred to as interactive site segregation [32]. If competing parasite species alter their position in the host or the food they ingest in response to the presence of a competitor, then the functional importance of dominant species in determining the numerical composition of the community will be reduced but usually not nullified.

\subsection{Indirect influence of one parasite species on others}

The bulk of the research carried out on the structuring of parasite communities has focussed on the role of direct competition among parasite species [4, 5, 21]. Little is known of indirect effects of one parasite species on others, for instance effects mediated by changes in host phenotype. As emphasised earlier, many parasite species can modify the phenotype of their hosts [20,21]. Often this occurs in parasites with complex life cycles, in which the phenotype of an intermediate host can be manipulated to facilitate the transmission of the parasite to its next host. This manipulation can also coincidentally alter the host in ways that make it a more suitable habitat for other parasite species (Fig. 2b). Also, many parasites interfere with the defence mechanisms of the hosts [33], and immunosuppressed hosts can therefore become more suitable hosts for other parasite species. These processes lead to positive associations between parasite species without any direct interaction between them being involved. Any parasite modifying the host in ways that create or maintain habitats for other parasites is potentially an ecosystem engineer with a functionally important role in the parasite community.

The host, once modified by one parasite species, may then offer benefits to other parasites that go beyond proximate advantages such as a depressed immune system or an increased availability of resources. For example, gammarid 
amphipods harbouring the trematode Microphallus papillorobustus display an aberrant behaviour that makes them more susceptible to predation by aquatic birds, the parasite's definitive hosts [34]. Another trematode, Maritrema subdolum, also exploits gammarids and aquatic birds in succession, but is incapable of modifying the behaviour of its gammarid hosts. However, this trematode prefers to infect amphipods already parasitised by $M$. papillorobustus [35]. Maritrema subdolum thus preferentially exploits the portion of the gammarid population modified by $M$. papillorobustus, benefitting from a higher rate of transmission to the definitive host. The numerical impact of $M$. papillorobustus on the M. subdolum population may therefore be quite important. There are many known systems in which a parasite species capable of manipulating its intermediate host coexists with other species with identical life cycles [36]. The functional importance of parasite species that induce changes in host phenotype for the structuring of parasite communities in invertebrate hosts is probably far from negligible.

Similarly, if a parasite species manipulates its intermediate host in a way that facilitates its transmission to its definitive host, other parasites that use a different definitive host should avoid hosts manipulated by that parasite. If the abundance of the manipulator parasite species increases, we may expect that the abundance of other species would decrease since the availability of suitable, non-manipulated intermediate hosts would also decrease. There are no doubt many situations in which the indirect consequences of infection by one parasite species are of great importance for other parasites; we have only scratched the surface and this should be a promising research direction in parasite community ecology.

\section{Integrating community levels: an example}

The research described in the previous sections has focussed on one particular level of the overall community, either the community of free-living organisms or the communities of parasites living inside those free-living organisms. There is a great need to consider all levels when assessing the functional importance of a species, whether a parasite or not, for community structure and the maintenance of biodiversity. This last section will summarise work in progress on the role of a particular trematode species in regulating the abundance of its intermediate host, of the epibiotic invertebrates living on the intermediate host, and of the other parasite species exploiting the intermediate host. The study examined the functional importance of a single parasite species in a softsediment intertidal community on the South Island of New Zealand. Past studies on the structuring of intertidal soft-sediment communities have focussed on the roles of predation and competition [37]. Most invertebrates living in soft-sediment intertidal zones are parasitised by one or more parasite species, and ignoring these parasites in community studies can be grossly misleading [38]. Focussing on a single parasite species and its effects will not provide a complete picture either; nevertheless, it serves to illustrate the many influences that parasites can have at all levels of a community. I will first provide some ecological background on the intertidal ecosystem in which the work was done, and then discuss the effects of the parasite that have been identified thus far (summarised in Fig. 3).

\subsection{The study system}

One of the two main players in our system is the cockle Austrovenus stutchburyi, possibly the most abundant bivalve in sheltered, soft-sediment shores of New Zealand [39]. There may be between 100 and 300 cockles per $\mathrm{m}^{2}$ in some places along the Otago coast, South Island. This high cockle density is not apparent to the naked eye: cockles usually live buried $1-2 \mathrm{~cm}$ below the surface of the sediments, with only their inhalant and exhalant siphons reaching the surface. Oystercatchers (Haematopus spp.) are probably the only predators of cockles in the areas we studied. Despite their buried lifestyle, cockles provide attachment substrate for a variety of invertebrates. Often cockle shells represent the only hard substrate in soft-sediment intertidal zones, 


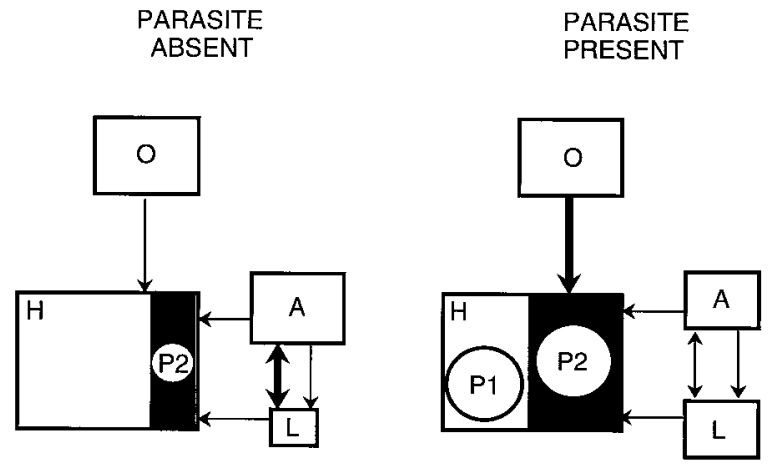

Fig. 3. Schematic summary of the effects of the trematode Curtuteria australis on some members of the New Zealand soft-sediment intertidal community. When $C$. australis, $\mathrm{P} 1$, is present, predation on cockles, $\mathrm{H}$, by oystercatchers, $\mathrm{O}$, is increased but the impact on the cockle population is probably not measurable. The presence of $C$. australis also causes an alteration in host phenotype that benefits limpets, L, perhaps at the expense of anemones, A. Finally, the presence of $C$. australis allows the other trematode $C$. pectinata, $\mathrm{P} 2$, to occur at higher abundance. The alteration in cockle phenotype is illustrated by the black shading. The relative abundances of different species with and without $C$. australis are indicated by the sizes of boxes and circles. Competitive interactions are illustrated by two-way arrows; other arrows indicate one-sided exploitative interactions. The strength of the interaction is proportional to the thickness of the arrow.

and partially exposed cockles (and even buried cockles closest to the surface) harbour a rich epifauna. In particular, some limpets, barnacles, sea anemones and polychaetes are only found associated with cockles, and form a distinct epibiotic community [39]. Other invertebrates and algae are often found attached on cockles but can also use other types of substrates; these include chitons, mussels, bryozoans and sea lettuce.

The second major player in the system is naturally a parasite, the trematode Curtuteria australis (Echinostomatidae: Himasthlinae). Adult C. australis live in the intestine of oystercatchers [40]. Their eggs pass out in the faeces of their host and hatch in water, where miracidia penetrate whelks, the parasite's first intermediate host. Cercariae produced in whelks then go on to infect cockles, penetrating via the inhalant siphon [40]. Like other himasthline trematodes [41], the metacercarial cysts of C. australis are only found in the foot of their cockle host. In heavily-infected cockles, we found that not only foot tissue is replaced by metacercariae, but also the size of the foot relative to the shell is significantly reduced [42]. The immediate result of this parasite-induced change in host phenotype is that the ability to burrow properly diminishes as the intensity of infection increases. We found that heavily-infected cockles can not even reach the substrate with their grossly stunted foot when lying at the surface of the sediments [42]. In field experiments, we observed that cockles found lying at the surface would stay there for days, whereas buried cockles dug up and then placed on the sediments would quickly burrow again and disappear. In the light of the life cycle of the parasite and the voluminous literature on parasite manipulation of host phenotype [20,21], we interpreted this handicapping of the host as an adaptation of the parasite serving to increase predation by oystercatchers and thus transmission of the parasite to its definitive host. In the context of the intertidal community, an indirect effect of the parasite manipulation is to split the cockle population into two distinct ecological categories, buried cockles and surface cockles, the latter existing solely because of the parasite.

Cockles have other parasites in the areas where we performed our study. Another trematode, Cercaria pectinata, has long been known to infect cockles along the Otago coast [43]. The complete life cycle of this species is still unknown. Cockles are used as first intermediate hosts, in which the trematode multiplies asexually to form thousands of cercariae contained in several hundred sporocysts. No other mollusc has been found infected with $C$. pectinata, and we assume that cockles are the only suitable host for the parasite at this stage in its cycle. Cockles are also hosts for parasitic copepods [44] and pea crabs (Pinnotheres sp.). The latter may not be a true parasite but instead a commensal; however it is the only other metazoan endosymbiont found in cockles in our study sites.

\subsection{Effect on the bivalve community}

One way in which the trematode $C$. australis could have a direct effect on the bivalve commu- 
nity would be to increase predation rates on cockles and thus alter the abundance of cockles relative to that of other bivalves. We performed field predation experiments, in which we quantified predation rates on normal, buried cockles and on manipulated, surface cockles. We found that predation by oystercatchers was about seven times higher on surface cockles than on buried cockles [42]. Given the nature of the parasite manipulation, the parasite's life cycle, and the foraging behaviour of oystercatchers, this result is not entirely surprising.

From an individual perspective, heavy infection by $C$. australis decreases survival of cockles; but what are the effects on the population and on the intertidal community? This is proving difficult to estimate precisely. However, given the fact that cockles are extremely abundant, by far the dominant bivalve in the soft-sediment zones, and that oystercatchers are not very abundant and remove only a tiny fraction of cockles from the population, a conservative answer would be that $C$. australis has a trivial influence on that level of the community. In the absence of the parasite, oystercatchers would probably focus their efforts on cockles that have been partially exposed by water movement and thus remove the same number of individuals from the population. Thus, even though the parasite increases host mortality, its effect on the host population and the host's relative abundance in the community may be negligible (Fig. 3). As seen below, the indirect effects of $C$. australis on non-host species appear more important.

\subsection{Effect on the community of epibionts of cockles}

The many obligate or facultative epibionts of cockles obtain one key resource from cockles: attachment space in a habitat practically devoid of other hard substrates. Space on cockles is in short supply because most cockles are buried too deep into the sediments to be available for attachment. We might therefore expect that epibiotic invertebrates compete for space. Indeed, we found strong negative correlations between the number of sea anemones, Anthopleura aureo- radiata, and the number of limpets, Notoacmea helmsi, on cockles from three different sites on the East coast of the South Island [45]. These two species are by far the most common epibionts of cockles in our study sites; they attach either to cockles lying at the surface of the sediments, to partially exposed cockles, or to cockles buried under less than $1 \mathrm{~cm}$ of sediments. Competition for space is not the only antagonistic interaction between these two species. In the laboratory, we clearly demonstrated that predation of limpets by anemones is possible when they share the same cockle shell [45].

There should thus be selective pressures on limpets to avoid settling next to anemones, in spite of constraints imposed by the limited substrate space available for attachment. Here is where the trematode $C$. australis comes in. As a consequence of the change in host phenotype induced by the parasite, more cockles are exposed at the surface of the sediments and more substrate becomes available for colonisation by epibionts. The parasite acts as a true ecosystem engineer, altering the state of living material in a way that increases the resources available to other organisms in the community [22-24]. This indirect consequence of host manipulation can serve to maintain local biodiversity by facilitating the coexistence of many epibiotic species.

In the field we observed twice as many limpets on cockles manipulated by $C$. australis than on normal, buried cockles [45]. This bias was confirmed in a field colonisation experiment, in which we placed surface and buried cockles in a protected area of the intertidal zone and allowed a few weeks for limpets to become established. As expected they showed a very strong preference for surface cockles. Anemones, on the other hand, are significantly more abundant on cockles buried just under the sediments' surface than on cockles lying at the surface [45]. A dessication test showed that limpets are five times more likely than anemones to survive a $1 \mathrm{~h}$ exposure to air and sunshine, which may explain why anemones prefer to be surrounded by moist sediments at low tide. All these results suggest that the trematode $C$. australis is functionally important for the community of epibionts of cockles. 
By altering the phenotype of cockles, it creates a new type of substrate that allows limpets to coexist with anemones by decreasing competition for space between these two epibionts (Fig. 3). The parasite's presence may be largely responsible for the presence of limpets in some given areas. How it relates with the abundance of other species of epibionts, such as polychaetes and bryozoans, remains to be determined.

\subsection{Effect on the parasite community}

The alteration in host phenotype induced by $C$. australis may also have indirect consequences for other parasite species exploiting cockles. All metazoan parasites of cockles found in our study sites enter the host through the inhalant siphon. Cockles manipulated by $C$. australis lie at the surface with their siphon opening $1-2 \mathrm{~cm}$ above the substrate, instead of right at the surface like that of buried cockles. This may impair or improve host location by other parasites.

In a large sample of cockles collected from one site, we found that surface cockles manipulated by $C$. australis were approximately five times more likely to harbour sporocysts of the other trematode, C. pectinata, than buried cockles [46]. The reasons for this bias are unknown but may have something to do with the swimming behaviour of the miracidium of $C$. pectinata. In any event, the manipulating trematode $C$. australis appears important for the maintenance of the trematode $C$. pectinata in the cockle population; without the modification in cockle phenotype induced by $C$. australis, the abundance of $C$. pectinata might be much lower (Fig. 3). Whether similar indirect effects also modulate the abundance of parasitic copepods and pea crabs living in cockles remains to be determined.

\section{Conclusion}

In the eyes of the community ecologist, all species are not equal. The removal of certain species from a community would have more drastic consequences than the removal of other species. Surely, to evaluate the functional import- ance of a parasite species in the overall community and in the maintenance of biodiversity, one must look both at its direct and indirect influence on all members of the community. Few studies attempt to do so. Most focus either on the direct impacts on host communities, or on direct interactions among parasite species and their effects on the parasite community. Using an example from the soft-sediment intertidal community in New Zealand, I have tried to show how approaching the community as a whole and looking at both obvious and subtle effects of parasites can help identify functionally important species. The trematode studied, despite directly increasing the mortality of its host, probably does not influence its population. However, it indirectly modulates the abundances of several other non-host species. This example is most probably not unusual, especially among aquatic ecosystems. Several parasite species modify the phenotype of their host in some manner; the consequences of these modifications for other species have simply not been investigated yet. Parasites that cause marked shifts in the spatial distribution of their hosts (e.g. Curtis [47]) are particularly promising for this type of study. To the people that matter, i.e. the educated taxpayers and the funding agencies, biodiversity is a buzzword these days. The challenge for parasitologists is now to show that parasites play important, if often subtle, roles in maintaining biodiversity, and that their study (and conservation!) is essential.

\section{Acknowledgements}

This paper is loosely based on a keynote address presented at the 1998 meeting of the Australian Society for Parasitology, in Melbourne. I thank Ian Beveridge and the Society for inviting me.

\section{References}

[1] Freeland WJ. Parasites and the coexistence of animal species. Am Nat 1983;121:223-36. 
[2] Price PW, Westoby M, Rice B et al. Parasite mediation in ecological interactions. Annu Rev Ecol Syst 1986; 17:487-505.

[3] Minchella DJ, Scott ME. Parasitism: a cryptic determinant of animal community structure. Trends Ecol Evol 1991;6:250-4.

[4] Esch GW, Bush AO, Aho JM. Parasite communities: patterns and processes. London: Chapman and Hall, 1990.

[5] Sousa WP. Patterns and processes in communities of helminth parasites. Trends Ecol Evol 1994;9:52-7.

[6] Poulin R. Species richness of parasite assemblages: evolution and patterns. Annu Rev Ecol Syst 1997;28:341-58.

[7] Payne RT. A note on trophic complexity and species diversity. Am Nat 1969;103:91-3.

[8] Hurlbert SH. Functional importance vs keystoneness: reformulating some questions in theoretical biocenology. Aust J Ecol 1997;22:369-82.

[9] Hurlbert SH. The nonconcept of species diversity: a critique and alternative parameters. Ecology 1971;52:57786.

[10] Park T. Experimental studies of interspecies competition. I. Competition between populations of the flour beetles, Tribolium confusum Duval and Tribolium castaneum Herbst. Ecol Monogr 1948;18:265-308.

[11] Yan G, Stevens L, Goodnight CJ, Schall JJ. Effects of a tapeworm parasite on the competition of Tribolium beetles. Ecology 1998;79:1093-103.

[12] Thomas F, Renaud F, Rousset F, Cézilly F, de Meeûs T. Differential mortality of two closely related host species induced by one parasite. Proc $\mathrm{R}$ Soc London B 1995;260:349-52.

[13] Jensen T, Jensen KT, Mouritsen KN. The influence of the trematode Microphallus claviformis on two congeneric intermediate host species (Corophium): infection characteristics and host survival. J Exp Mar Biol Ecol 1998;227:35-48.

[14] Warner RE. The role of introduced diseases in the extinction of the endemic Hawaiian avifauna. Condor 1968;70:101-20.

[15] van Riper C, III, van Riper SG, Goff ML, Laird M. Epizootiology and ecological significance of malaria in Hawaiian land birds. Ecol Monogr 1986;56:327-44.

[16] Poulin R, FitzGerald GJ. The potential of parasitism in the structuring of a salt marsh stickleback community. Can J Zool 1987;65:2793-8.

[17] Schall JJ. Parasite-mediated competition in Anolis lizards. Oecologia 1992;92:58-64.

[18] Arneberg P, Folstad I, Karter AJ. Gastrointestinal nematodes depress food intake in naturally infected reindeer. Parasitology 1996;112:213-9.

[19] Moore J, Gotelli NJ. A phylogenetic perspective on the evolution of altered host behaviours: a critical look at the manipulation hypothesis. In: Barnard CJ, Behnke
JM, editors. Parasitism and host behaviour. London: Taylor and Francis, 1990;193-233.

[20] Poulin R. 'Adaptive' changes in the behaviour of parasitized animals: a critical review. Int $\mathbf{J}$ Parasitol 1995;25:1371-83.

[21] Poulin R. Evolutionary ecology of parasites: from individuals to communities. London: Chapman and Hall, 1998.

[22] Jones CG, Lawton JH, Shachak M. Organisms as ecosystem engineers. Oikos 1994;69:373-86.

[23] Jones CG, Lawton JH, Shachak M. Positive and negative effects of organisms as physical ecosystem engineers. Ecology 1997;78:1946-57.

[24] Thomas F, Poulin R, de Meeûs T, Guégan J-F, Renaud F. Parasites and ecosystem engineering: what roles could they play? Oikos 1999;84:167-71.

[25] Høeg JT. The biology and life cycle of the Rhizocephala (Cirripedia). J Mar Biol Assoc UK 1995;75:517-50.

[26] Sousa WP. Interspecific interactions among larval trematode parasites of freshwater and marine snails. Am Zool 1992;32:583-92.

[27] Sousa WP. Interspecific antagonism and species coexistence in a diverse guild of larval trematode parasites. Ecol Monogr 1993;63:103-28.

[28] Dobson AP. The population dynamics of competition between parasites. Parasitology 1985;91:317-47.

[29] Kuris AM, Lafferty KD. Community structure: larval trematodes in snail hosts. Annu Rev Ecol Syst 1994;25:189-217.

[30] Bush AO, Holmes JC. Intestinal helminths of lesser scaup ducks: an interactive community. Can $\mathbf{J}$ Zool 1986;64:142-52.

[31] Stock TM, Holmes JC. Functional relationships and microhabitat distributions of enteric helminths of grebes (Podicipedidae): the evidence for interactive communities. J Parasitol 1988;74:214-27.

[32] Holmes JC. Site segregation by parasitic helminths: interspecific interactions, site segregation, and their importance to the development of helminth communities. Can J Zool 1973;51:333-47.

[33] Wakelin D. Immunity to parasites: how animals control parasitic infections. London: Edward Arnold, 1984.

[34] Helluy S. Relations hôtes-parasites du trématode Microphallus papillorobustus (Rankin, 1940). III. Facteurs impliqués dans les modifications du comportement des Gammarus hôtes intermédiaires et tests de prédation. Ann Parasitol Hum Comp 1984;59:41-56.

[35] Thomas F, Mete K, Helluy S et al. Hitch-hiker parasites or how to benefit from the strategy of another parasite. Evolution 1997;51:1316-8.

[36] Thomas F, Renaud F, Poulin R. Exploitation of manipulators: 'hitch-hiking' as a parasite transmission strategy. Anim Behav 1998;56:199-206.

[37] Wilson WH. Competition and predation in marine softsediment communities. Annu Rev Ecol Syst 1991;21:22141. 
[38] Sousa WP. Can models of soft-sediment community structure be complete without parasites? Am Zool 1991;31:821-30.

[39] Morton J, Miller M. The New Zealand sea shore, 2nd edn. London: Collins, 1973.

[40] Allison FR. Life cycle of Curtuteria australis n.sp. (Digenea: Echinostomatidae: Himasthlinae), intestinal parasite of the South Island pied oystercatcher. NZ J Zool 1979;6:13-20.

[41] Lauckner G. Impact of trematode parasitism on the fauna of a North Sea tidal flat. Helgoländ Meeresunter 1984;37:185-99.

[42] Thomas F, Poulin R. Manipulation of a mollusc by a trophically transmitted parasite: convergent evolution or phylogenetic inheritance? Parasitology 1998;116:431-6.
[43] Chilton C. On the occurrence of a species of cercaria in the cockle Chione stutchburyi. Trans Proc NZ Inst 1905;37:322-5.

[44] Humes AG. Ostrincola and Pseudomyicola (Crustacea: Copepoda: Poecilostomatoida) associated with marine bivalve molluscs on the Pacific coast of Panama. Proc Biol Soc Washington 1984;97:589-600.

[45] Thomas F, Renaud F, de Meeûs T, Poulin R. Manipulation of host behaviour by parasites: ecosystem engineering in the intertidal zone? Proc R Soc London B 1998;265:1091-6.

[46] Poulin R, Hecker K, Thomas F. Hosts manipulated by one parasite incur additional costs from infection by another parasite. J Parasitol 1998;84:1050-52.

[47] Curtis LA. Vertical distribution of an estuarine snail altered by a parasite. Science 1987;235:1509-11. 